\title{
Breast Milk Substitutes: Changing Ideas
}

\author{
Claude Billeaud \\ CIC Pediatric 1401 CHU Pellegrin, 33000 Bordeaux, NewAquitaine, France
}

\begin{abstract}
Abstact: Breast milk is the model for infant feeding. In the absence of breast milk, substitutes have been created whose composition attempts to copy that of breast milk. However, it is impossible to make from cow's milk the copy of human milk given that it is composed of a thousand substances which have for some the function of nutrients and for others (the most numerous) properties bioactive. In addition, there is no fixed milk for the same mother but mothers whose composition varies over time: colostrum (first 5 days, transition milk ( 5 to 30 days), mature milk after one month, but also during the day: milk is not the same in the morning, at noon and in the evening, and even worse: at the beginning and at the end of the summer. The mother's diet: although milk proteins and carbohydrates are only slightly influenced, there is a strong correlation between dietary lipids and breast milk, as well as minerals, vitamins and trace elements. On the other hand, the composition of breast milk that gave birth to a premature child is higher in protein than that of the milk of a mother of a newborn baby. Despite all these constraints, doctors and industrialists of the agro-alimentary do not cease to make progress to create formulas of milk more and more close to the nutritive values of the human milk.... But it is an endless challenge; In fact when a complex protein or oligosaccharides and polyunsaturated fatty acids are discovered in the mother's milk, it is necessary to evaluate by means of studies that are often long to discover their exact role and to demonstrate the correct dosage to be added in the formulas.
\end{abstract}

Key words: Formulas, lipids, fat, carbohydrates, prebiotics, probiotics, HMO, hydrolysates.

\section{Introduction}

Before 1991 there was a heterogeneity between the different milk formulas, a European Directive of 1991 applied in 1994 defined well the first classification of formulas of milks for the children of 0 to 3 years. There are infant formulas of 0 to 4 months, follow-on formulas of 4 to 12 months and infant formula of 1-3 years [1, 2].

Over the years, several decrees have adapted the milk according to the products found in mother's milk often having bioactive properties such as proteins, oligosaccharides, polyunsaturated fatty acids; Thus, in 2005, the ESPGHAN Nutrition Committee [3] developed the recommended dosage of the various nutrients. However, the history of the evolution of milk products continues unabated.

\section{Evolution of Ideas}

\subsection{Evolution of Ideas on Proteins}

Proteins [4] ingested with breast milk provide

Corresponding author: Claude Billeaud, MD, PhD, research fields: Neonatology \& nutrition. essential amino acids for the new protein synthesis for growth and replacement of urine, stool and skin losses. The protein gain in the body of an infant is highest in the first months when the protein concentrations in breast milk are higher than in the later stages of lactation. Pre-term births have higher protein requirements than term infants and require protein supplements during feeding with breast milk. Thanks to our better understanding of the evolution of proteins in breast milk during the lactation stages, new formulas for infants with lower protein concentration but better protein quality have been created, tested successfully and are now available in numerous countries. In addition to providing essential amino acids, bioactive proteins in breast milk can be classified into 4 major functions, i.e. protect against microbial aggressions and immune protection, promote digestive functions, develop the intestine and be carriers of other nutrients. The individual proteins and their proposed bioactivities are summarized in this document in brief. Some proteins, such as lactoferrin and $\operatorname{sg} \mathrm{A}$, have been studied to the extreme for their 
biological functions, while others may require more data to confirm their proposed functions.

This graph shows the decrease in total amino acids following the decrease in the protein level, while the level of amino acids remains stable despite protein levels between 0.7 and $1 \mathrm{~g} / 100 \mathrm{~mL}$ after 4 months of lactation $[5,6]$.

Proteins play a major role in the gastric evacuation rate, which was measured by following the technetium-labeled bolus to search for gastroesophageal reflux in 200 infants aged 0 to 1 year. Fifty percent had no GERD and we looked at the milk that the child drank so we could distinguish a classification:

Fast milk: mother milk, HA milks, acidified milks, milk modified in summary those with a casein/soluble protein ratio of more than 1 , and slow milks: unmodified milks 1st age, 2nd milk, cow's milk.

In all, the higher the casein content, the slower the digestion, but the better the satiety. Example if cow's milk is given to an infant $50 \%$ of the bottle remains after 2 hours; Conversely breast milk containing $30-40 \%$ casein and $60 \%$ soluble protein, only $18 \%$ of the bottle remains after 2 hours and the child claims more frequently.

\subsection{Evolution of Ideas on Lipids}

The lipid composition of breast milk varies according to the mother's diet.

The rate can vary from 2 to $7 \mathrm{~g} / \mathrm{L}$ and the median is $3.6 \mathrm{~g} / 100 \mathrm{~mL}$.

Most breast milk lipids are made of an emulsion with globule fat enveloped in a 3-layer lipid membrane made of phospholipids, cholesterol, sphingolipids and a container: triglycerides which represent $98 \%$ of the total lipids of the mother's milk.

In terms of certain fatty acids, they play a role in neurosensory development: Long-chain polyunsaturated fatty acids (PUFA-LC) of the omega3 family and omega6: the precursors with 18 carbon atoms are distinguished from omega 6 , linoleic acid
(LA, C18: 2n-6) of omega 3, $\alpha$-linolenic acid (ALA, 18: 3n-3) which will elongase and desaturate (desaturases). The metabolic problem is that these two families are in metabolic competition because they use the same elongases and desaturases, knowing that it is the $\omega-3 \mathrm{~s}$ that have the highestd. The affinity for these enzymes will require 6 times more linoleic acid than $\alpha$-linolenic acid so that both families can metabolize to arachidonic acid (ARA, C20: 4n-6) and docosahexaenoic acid or DHA. Too much linoleic acid is added-Linolenic acid is not converted to DHA The LA/ALA ratio recommended by ESPGHAN (2005) [3] is 5-15, this standard is too large, the French Nutrition Committee recommends 6 and we confirmed this ratio in a randomized multicenter study that showed that between milk and ratio was 32 versus 6 , there was even a transformation of $\alpha$-linolenic acid into DHA in the premature infant [7]. However, there were $20 \%$ which do not possess the FADS gene which activates the desaturases, so in the diet of the nursing mother it is necessary to bring not only the precursors but also the DHA and the ac., arachidonic. We have followed the evolution of fatty acids of maternal milks in France [8] over the past 17 years and noticed through this study the doubling of $\alpha$-linolenic acid from $0.5 \%$ of total fatty acids to about $1 \%$. But only by bringing a supplement to the nursing mother of $25 \mathrm{~g} / \mathrm{d}$ of rapeseed oil $+25 \mathrm{~g}$ of margarine omega3 St Hubert that we reach (see curves) $2.15 \%$ $\alpha$-linolenic acid which is in the recommended need between $1.7 \%$ and $4 \%$ of the total fatty acids and has reached the ratio LA/ALA $=5.5$ in breast milk, on the other hand it is only the consumption of mackerel 2 times $170 \mathrm{~g} /$ week (approximately $350 \mathrm{mg} /$ day of DHA) which increased the DHA level to $0.5 \%$ [9].

So we see that the mother's model for lipids, depends closely on the diet.

What to put in infant milks as precursors and polyunsaturated fatty acids at very long chain when we see the variations in different countries of the world where DHA varies; there is maternal milk 
deficient in DHA $<0.17 \%$ and maternal milks at $2.7 \%$ in China Maritime.

Most premature infants are supplemented with $0.20 \%$ DHA and ARA (approximately $18 \mathrm{mg} / 100 \mathrm{~mL}$ ) and our opinion is that they are insufficiently enriched since DHA in the last trimester of pregnancy, fetus needs about $50 \mathrm{mg} / \mathrm{kg} /$ day of DHA. Koletzko [3] said that there is no maximum value, he advises for premature milks a supply of $60 \mathrm{mg} / 100 \mathrm{~mL}$ of milk.

If premature babies are given supplemental DHA and ARA for better brain and visual development, many are faced with the question of supplementation in term infants.

In view of our experience we can advise around $0.5 \% / 100 \mathrm{~mL}$ of DHA and ARA

For ALA between $1.7 \%$ and $4 \%$ of total fatty acids/100 $\mathrm{mL}$ and LA, 5-6 times more with a ratio of LA/ALA between 5 and 7 .

Other lipids play an important role in infant development:

Gangliosides and neutral glycosphingolipids were obtained from the cow's milk fat cell membrane [10] which could be introduced into a milk formula with good tolerance. Breast milk has similar levels of gangliosides and neutral glycosphingolipids, with breast milk having more GM3 and less GD3. Gangliosides GM3 and GD3 have the property of binding the enterotoxigenic strains of escherichia coli, they also play a role in brain development.

\section{Formulas Classification}

\subsection{Milks from 0 to 4 Months}

(1) Modified milk (this means that from cow's milk the Cas/PS ratio was changed to $80 \% / 20 \%$ )

Casein content is lower $40 \%$ and $60 \%$ of soluble proteins: Cas/PS $<1$.

This is the formula that comes closest to the protein composition of breast milk.

But as there is little casein the child claims faster, and he cries, so the mother gives him more often to eat and this results in an excess of ration.
In addition, sugars are represented only by lactose as opposed to mother's milk, excess lactose which turns into lactic acid which manifests itself as colic and the baby cries because it suffers. Mom thinks he is hungry and gives him even more. It sets up a vicious circle.

So you end up with an uncomfortable baby and a risk of overeating and GERD.

(2) Un-Modified milk

Unmodified milk with a Cas/PS ratio $<1$

"It is satiety formulas" We move away from the mother's milk model with less soluble proteins, but we must include the major soluble protein: lactalbumin, a major protein in breast milk $(0.35$ $\mathrm{g} / 100 \mathrm{~mL}$ ).

Sugar: 70\% lactose and 30\% dextrin-maltose and with less coronary coronary. The mother has a peaceful infant and less regurgitation because the caseins have a high molecular weight and flocculent to the bottom of the stomach.

3.2 Milks or Preparations of 5 to 12 Months: Preparations or Follow-up Milk

These are milks whose protein composition is Cas/PS $>1$ whose protein level is higher than the infant formula 1.6-1.8 gr/100 mL.

But we move away from the model of breast milk with more casein and a higher protein level than breast milk which is at this period of 0.7 to $1 \mathrm{gr} / 100 \mathrm{~mL}$.

However, as the protein level is too high during the first months, predisposing to future obesity, studies are being carried out to make milk immediately at a rate close to that human milk. At the present time, milks containing $1.3 \mathrm{~g} / 100 \mathrm{~mL}$ are available, however, providing all the essential amino acids.

In addition they are enriched with vitamins, iron and essential fatty acids.

\subsection{Dairy Foods for Infants (1-3 years)}

The question posed by parents or even doctors: why not switch to cow's milk? 
Lists arguments against cow's milk between 0-3 years.

(1) Too much protein attention future obesity

(2) Too much saturated fatty acids and no essential fatty acids ( $40 \%$ of RDAs in milks)

(3) No iron in cow's milk and $60 \%$ of RDAs in growth milk

Six $\mathrm{mg} / 500 \mathrm{~mL}$ for $10 \mathrm{mg} / \mathrm{d}$ needs. Now it is the period of nutritional anemia at this age for want of iron; Gold with the intake of animal proteins and cow's milk, we do not reach the $10 \mathrm{mg} / \mathrm{d}$.

\section{Bioactive Infant Formula}

\subsection{Milks with Prebiotics}

Through their actions on the intestine, oligosaccharides affect directly and indirectly mucosal and systemic immunity of infants. A large number of studies have shown that oligosaccharides can influence the proliferation and maturation of intestinal cells (such as crypt cells and goblet cells). In addition, oligosaccharides can also modulate gene expression in the intestinal epithelium. Together, they affect the function of the intestinal barrier which, in turn, regulates local and systemic immunity. Research shows that there are different types of prebiotics, in a similar way as there are different types of probiotics. With prebiotics, the main differentiating factor is the length of the chemical chain-short chain; The medium chain or long chain determines where in the gastrointestinal tract the prebiotic has its effect, and how the benefits can be felt by the host.

Common prebiotics include: inulin, fructo-oligosaccharides

(FOS), galacto-oligosaccharides (GOS), lactulose and lafinose. Human milk contains: $1.2 \mathrm{~g} / 100 \mathrm{~mL}$ of oligosaccharides and 130 different molecules, the most represented being FOS and GOS.

\subsubsection{Practical Implications}

Human milk contains a higher concentration and greater structural diversity and a greater degree of fucosylation than milk oligosaccharides of other species, including cow's milk from many infant formulas. The commercially available oligosaccharides are increasingly available and suggest that supplementing infant formulas with oligosaccharides is safe and beneficial to human infants. There are also potential applications of oligosaccharides as prophylactic and therapeutic treatments for those who are immunocompromised and at high risk of infection. Through various actions on intestinal function and the intestinal microbiota, human milk oligosaccharides can modulate the local and systemic immunity of the infant [11-14].

\subsection{Milks with Probiotics}

Probiotics are microorganisms capable of modifying the intestinal flora by having a demonstrated beneficial effect on health. Different studies highlight the beneficial effect and safety of certain probiotics, including bifidobacterium lactis strain Bb12, and lactobacillus GG [15] and lactobacillus Reuteri.

\subsection{Fermented or Acidified Milk}

They are characterized by a biological acidification of milk under the action of fermentative bacteria (Gallia lactofidus, GuigozPelargon ${ }^{\circledR}$ : Lactobacillus Reuteri). Casein, which is finely flocculated, is better tolerated. The lactose content is often reduced. This type of products therefore finds its indications in the correction of minor digestive disorders (colic, transit disorder) fermented milk, in case of difficulty in digesting infant formula.

\section{Milk with Therapeutic Properties}

Hypoallergenic milks (HA milks), Thickened milks (AR milks), Soy milks.

\subsection{Hypoallergenic Formulas}

Their indication has a preventive purpose, at birth, in newborns at risk of atopy because of a family history (mother, father or sibling) which provided that 
it is continued, without interruption and exclusively, until at the age of 4 months, dietary diversification will be advanced to allow tolerant contact. As demonstrated, hydrolysates have a fast gastric emptying and are fast-acting milk (unsatisfied satiety, numerous and almost liquid stools). Hypoallergenic milks can also be proposed as a transient complement during the initiation of breastfeeding. The only milk that is shown by the GINI study [16] that it decreased atopic dermatosis by $40 \%$ was the Guigoz expert HA-partial hydrolysates of soluble protein (test over 15 years and more 2,000 children) is actually more effective than a pulsed hydrolyzate of soluble proteins.

\subsection{AR Milks as Anti-regurgitation or Thickened Milk}

They are thickened milks to decrease gastric emptying to treat GERD.

Two types of thickener: based on corn starch or rice or based on carob (Nutrilon AR, Guigoz expert AR ...).

They must be distinguished from the comforts which are to treat small regurgitations.

\subsection{Soy Base Preparations}

Do not have much interest except that they are poor in lactose. The only request would eventually be to meet the demands of a vegetarian mother.

\section{How to Choose Artificial Infant Formula}

In the event of failure or non-choice of breastfeeding, parents should be asked if the mother, father or siblings have an allergic ground:

- If yes, the choice is effective HA milk: Guigoz expert HA exclusively up to 4 months;

- If there is no allergic ground, first choose a modified milk enriched in PFA-LC DHA and arachidonic and precursors of omega 3 and omega 6 with prebiotics and/or probiotics.

But if there is a poor tolerance of the modified milk, choose as milk the acidified fermented.

\section{Lactose Free Milks, Protein Hydrolysates}

\subsection{Lactose-Free Milk}

The indications are the congenital or secondary intolerances in lactose.

Sometimes necessary in the treatment of acute diarrhea (child from 3 to 6 months).

\subsection{Hydrolysates or Semi-elementary Diets}

These are "mildew" milks in which proteins have a high hydrolysis, 20-50\% TCM, and lactose-free. So even with complete abrasion of the intestinal villi the milk is absorbed.

The indications are chronic diarrhea, allergy to cow's milk protein, gluten, cystic fibrosis, short hail, acute diarrhea of 0 to 3 months.

If hydrolysates are ineffective, a hydrolyzate is used as a last resort to form an amino acid solution (Neocate).

\section{Composition of Milk for Children}

We recommend advice from ESPGHAN formulas [3].

\section{References}

[1] Arrêté du 11 janvier 1994. modifiant l'arrêté du 1er juillet 1976 relatif aux aliments diététiques et de régime de l'enfance et l'arrêté du 30 mars 1978 relatif aux aliments lactés diététiques. JO 15.02.1994: 2552-9.

[2] DIRECTIVE 2006/141/CE DE LA COMMISSION du 22 décembre 2006 concernant les préparations pour nourrissons et les préparations de suite.

[3] Koletzko, B., Baker, S., Cleghor, G., Fagundes, N. U., Gopalan, S., et al. 2005. "Global Standard for the Composition of Infant Formula: Recommendations of an ESPGHAN Coordinated International Expert Group." Journal of Pediatric Gastroenterology and Nutrition 41: 584-99.

[4] Haschke, F., Halden, N., and Thakkar, S. K. 2016. "Nutritive and Bioactive Proteins in Breastmilk." Ann Nutr. Metab. 69: 17-26. DOI 10.1159/000452820.

[5] Garcia-Rodenas, C. L., Affolter, M., Vinyes-Pares, G., De Castro, C. A., Karagounis, L. G., Zhang, Y., et al. 2016. "Thakkar Amino Acid Composition of Breast Milk fromUrban Chinese Mothers." Nutrients 8 (10): 606. 
[6] Billeaud, C., Guillet, J., and Sandler, B. 1990. "Gastric Emptying in Infants with or without Gastro-Oesophageal Reflux according to the Type of Milk." Eur J Clin Nutr 44 (8): 577-83.

[7] Billeaud, C., Bougle, D., Sarda, P., Combe, N., Mazette, S., Babin, F., et al. 1997. "Effects of Preterm Infant Formula Supplementation with Alpha-Linolenic Acid with a Linoleate/Alpha-Linolenate Ratio of 6: A Multicentric Study." Eur J Clin Nutr 51 (8): 520-6.

[8] Boué-Vaysse, C., Billeaud, C., Guesnet, P., Couëdelo, L., Alessandri, J. M., Putet, G., and Combe, N. 2009. "Teneurs en acides gras polyinsaturés essentiels du lait maternel en France: évolution du contenu en acides linoléique etalpha-linolénique au cours des 10 dernières années." OCL 16 (1): 4-7.

[9] Mazurier, E., Rigourd, V., Perez,. P., Buffin, R., Couedelo, L., Vaysse, C., et al. 2017. "Effects of Maternal Supplementation with Omega-3 Precursors onHuman Milk Composition." Journal of Human Lactation 3: 1-10. DOI: 10.1177/0890334417691946.

[10] Billeaud, C., et al. 2014. "Safety and Tolerance Evaluation of Milk Fat Globule Membrane-Enriched Infant Formulas: A Randomized Controlled Multicenter Non-Inferiority Trial in Healthy Term Infants." Clinical Medicine Insights: Pediatrics 8: 51-60. DOI: 10.4137/CMPed.S16962.

[11] Kulinich, A., and Liu, L. "Human Milk Oligosaccharides:
The Role in the Fine-Tuning of Innate Immune Responses." Carbohydr Res. 432: 62-70.

[12] Donovan, S. M., and Comstock, S. S. 2016. "Human Milk Oligosaccharides Influence Neonatal Mucosal and Systemic Immunity.” Ann. Nutr. Metab. 69: 42-51.

[13] Sprenger, N., Ye Lee, L., De Castro, C. A., Steenhout, P., and Thakkar, S. K. 2017. "Longitudinal Change of Selected Human Milk. Oligosaccharides and Association to Infants' Growth: An Observatory, Single Center, Longitudinal Cohort Study.” PLOS ON 12 (2): e0171814.

[14] Geok, L. K., et al. 2016. "Correlation between Dietary Intake and Serum Ganglioside Concentrations: A Crosssectional Study among Malaysian Toddlers.” BMC Nutrition 2: 74.

[15] Chouraqui, J. P. 2002. "Place des laits infantiles dans l'alimentation du nourrisson et de l'enfant, in Goulet $\mathrm{O}$, Vidailhet $\mathrm{M}$ et coll. Alimentation de l'enfant en situation normale et pathologique." Progrès en Pédiatrie 13: 83-93.

[16] Von Berg, A., Fillipiak-Pittrof, B., and Shultz, H., et al. 2015. "Allergic Manifestation 15 Years after Early Intervention with Hydrolyzed Formulas-The GINI Study." Allergy 71 (2): 210-9.

[17] Chandra, R. K., and Hamed, A. 1991. "Cumulative Incidence of Atopic Disorders in High Risk Infants Fed Whey Hydrolysate, Soy, and Conventional Cow Milk Formulas.” Ann Allergy 67: 129-32. 